\title{
Simulation and Modeling Application in Agricultural Mechanization
}

\author{
R. M. Hudzari, M. A. H. A. Ssomad, R. Syazili, and M. Z. M. Fauzan \\ Department of Agriculture Science, Faculty of Agriculture and Biotechnology, Sultan Zainal Abidin University, \\ 21300 Terengganu, Malaysia
}

Correspondence should be addressed to R. M. Hudzari, mohdhudzari@unisza.edu.my

Received 10 April 2012; Accepted 20 August 2012

Academic Editor: Bauke Vries

Copyright ( 92012 R. M. Hudzari et al. This is an open access article distributed under the Creative Commons Attribution License, which permits unrestricted use, distribution, and reproduction in any medium, provided the original work is properly cited.

This experiment was conducted to determine the equations relating the Hue digital values of the fruits surface of the oil palm with maturity stage of the fruit in plantation. The FFB images were zoomed and captured using Nikon digital camera, and the calculation of Hue was determined using the highest frequency of the value for $R, G$, and $B$ color components from histogram analysis software. New procedure in monitoring the image pixel value for oil palm fruit color surface in real-time growth maturity was developed. The estimation of day harvesting prediction was calculated based on developed model of relationships for Hue values with mesocarp oil content. The simulation model is regressed and predicts the day of harvesting or a number of days before harvest of FFB. The result from experimenting on mesocarp oil content can be used for real-time oil content determination of MPOB color meter. The graph to determine the day of harvesting the FFB was presented in this research. The oil was found to start developing in mesocarp fruit at 65 days before fruit at ripe maturity stage of $75 \%$ oil to dry mesocarp.

\section{Introduction}

Basically, FFB are classified into four categories, black, hard, ripe: and overripe. However, for initial study, three types of FFB were used, ripe, unripe: and overripe. A camera vision system developed in this research is made up of two critical components. The first component is the hardware component that functions as an image acquisitioned for the system. The second component is the software part which analyzes the image captured by the hardware component. The system made prediction of FFB's maturity by processing the image captured. The main hardware system in this study is a digital camera to capture the image of the sample oil palm fruits and a light meter to detect intensity of the light. Sample pictures were taken in an oil palm plantation at MPOB, Bangi Lama, Selangor, Malaysia. Oil palm FFB maturity prediction in this research was done by determining the Hue values of oil palm at different stages of maturity. The prediction was also made on the relationship between Hue and oil content in the fruit.

The first monitoring period for oil palm fruit and lighting intensity was made starting from December 11, 2008 until
December 31, 2008. The second monitoring period was held from August 10, 2009 until October 06, 2009. All experiments were conducted within 8 to 9 weeks monitoring period. The FFB images captured were only after the fruit was completely grown with the fruit color skin changed at from black to reddish color. This is based on the study by Khalid and Abbas [1], who mentioned; at the stage of young fruits ripeness (within 7 to 11 weeks after flower was openanthesis), the color of fruits skin is black and only changes to reddish black from that duration. They mentioned the fruits, within 15 to 17 weeks after anthesis, had color surface of black plus reddish black while the oil percentage was less than $5 \%$, at 18 to 19 weeks after anthesis, the fruits color was reddish orange with 40 to $48 \%$ oil content, at 20 to 22 weeks, the fruit color surface was reddish orange plus orange, and at 22 to 23 weeks after anthesis, the fruit color was mostly orange with more than $50 \%$ oil content. The measurement of the oil content was based on percentage of oil with fresh mesocarp ratio. It is the wet base measurement.

This study was carried out from selected immature fruits (black color surface) until to overripe (orange color surface). The factor of lighting intensity under canopy of oil palm 
plantation was eliminated using Hue color value at specific camera parameters. The radiation from the sunlight was intercepted by the oil palm canopy by intercropping systems for growth resources of solar radiation and caused the intensity to decrease.

\section{Methodology}

The model was written in Visual Basic 6.0 and it was used to simulate and predict the suitable day to harvest the FFB. Only one progeny (Dura X Pisifera) was considered for this simulation model. The major input parameters and their mathematical expression were described. The major input variables of this equation are

(i) Hue value of the fruits image,

(ii) mesocarp oil content of the FFB (dry base measurement).

The simulation begun with an experiment which started from the fruit at unripe stage right until it reached overripe stage. Figure 1 shows the simulation of the overall project during the study. The Nikon coolpix 4500 digital camera and Keyence vision system were used to capture fruit image digitally. The camera was set to manual mode to make constant image output. The shutter speed of camera parameter was set to $1 / 8$, and the exposure was set to maximum. This parameter value was experimentally suitable to capture the FFB image for the whole day shift. The image was taken from under the canopy of oil palm tree in real plantation condition. After the capturing image session completed, 3 fruitlets were collected for the chemical test. These fruitlets picked must be from the outside of monitoring area. These steps were repeated until the FFB became overripened. More than 50 images were captured during the photography session.

During the running of the GUI program, the user chose the picture to be analyzed using VB 6.0. The user needs to feed the FFB image into the software and run the function to obtain histogram value of $R G B$ in monitored area of image. From maximum of $R, G$, and $B$ value, the value of Hue would be determined and compared with the Hue value from Keyence vision system. When the user wanted to analyze another FFB images, they have to repeat the same procedure as described earlier. Finally, the graph of oil content of mesocarp versus pixel value was plotted automatically in this program.

2.1. Calculation for Hue Value (HVM). The images captured were fed into the software, and these images were analysed using RGB histogram module in order to get maximum RGB value of all maturity stages of FFB image. Figure 2 shows the flow chart for calculation the Hue digital value. The color value of the images obtained from $R G B$ conversion value and would then verify by comparing the value obtained from Keyence vision system. In this experiment, only the Hue $(H)$ digital value was measured for determine the color surface of FFB while for saturation $(S)$ and intensity $(I)$ values, they are not used for color measurement. Same technique also was adopted by Abdullah et al. [2], which used single value of Hue for distinguishing different maturity stages of FFB, and the values for saturation and intensity were ignored. The histogram method which basically just a graphing of the frequency of each intensity of red, green, blue, or luminance in an image is used.

2.2. Calculation for Oil Extraction Ratio (OERM). Figure 3 shows the steps involved in calculating oil content in mesocarp ratio. The whole dry weight model was used to calculate oil-to-dry mesocarp ratio.

The whole dry weight calculation is as follows:

$$
\mathrm{WDW}=\mathrm{SST}-\mathrm{PST},
$$

where

$$
\begin{aligned}
& \text { SST }= \text { Sub }- \text { sample Weight }(\mathrm{Wt} .) \\
&+ \text { Thimble Wt. (weight of filter paper), } \\
& \text { PST }=\text { Post Soxhlet }+ \text { Thimble Wt. }
\end{aligned}
$$

The oil-to-dry Mesocarp was described as below:

$$
\underline{\underline{O}}=\frac{\left[\frac{\mathrm{WDW}}{(\mathrm{SST}-\mathrm{TW})}\right] \times 100,}{\mathrm{DM}}
$$

where WDW is the whole dry wt; TW is the thimble wt.

So, the average of oil content in mesocarp was calculated using the following equation:

$$
\begin{aligned}
& \text { Average oil content in meso }(\%) \\
& \qquad=\frac{\left[\mathrm{ODM}_{1}+\mathrm{ODM}_{2}+\mathrm{ODM}_{3}\right]}{3}
\end{aligned}
$$

Where $\mathrm{ODM}_{1}=$ oil to dry Mesocarp sub-sample 1; $\mathrm{ODM}_{2}=$ oil to dry Mesocarp sub-sample $2 ; \mathrm{ODM}_{3}=$ oil to dry Mesocarp sub-sample 3.

2.3. Calculation Day of Harvesting For FFB (DHM). Figure 4 shows the method to determine the days of harvesting. The relation of Mesocarp oil content with the Hue value of the FFB can be expressed by the following equation:

$$
\begin{aligned}
& \text { oil content (\% mesocarp) } \\
& \qquad=\text { constant parameter } * \text { Hue value }(0 \sim 255) .
\end{aligned}
$$

The correlation regression, $R^{2}$ shows the significant level on parameter relationship. The best regression correlation between Hue values with the mesocarp oil content is always 1. 


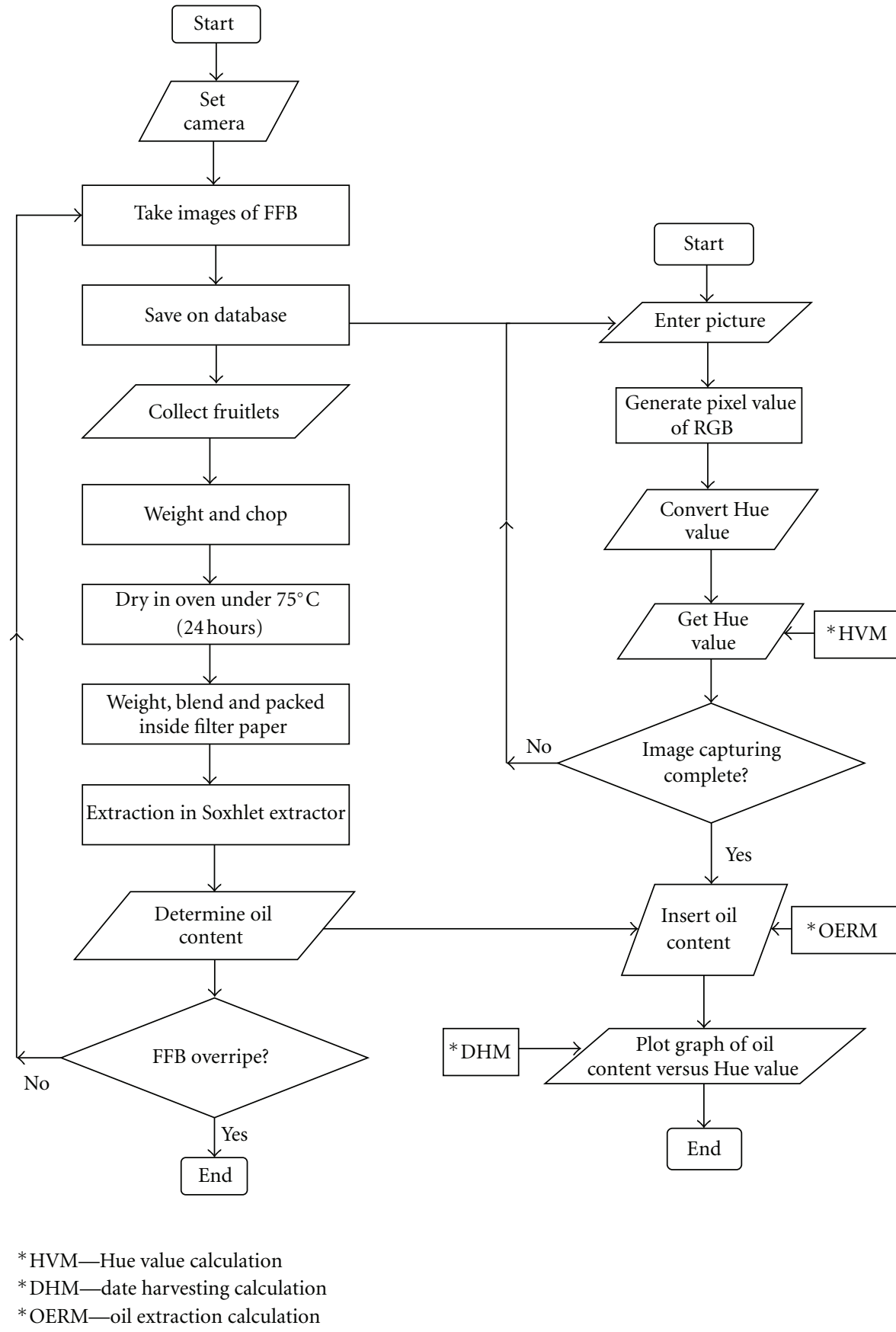

Figure 1: Flow chart of the involved work.

Figure 5 shows the flow charts for calculating harvesting day of FFB (DHM). The calculation and for the estimation day for harvesting the FFB model is described as below:

$$
\begin{gathered}
\frac{75 \%-0}{K-0}=\frac{0-65}{N-65}, \\
N=\left[\frac{(K-0)(-65)}{(75 \%-0)}\right]+65, \\
N=\frac{(-65 K)}{75 \%}+65,
\end{gathered}
$$

where $75 \%$ is the maximum mesocarp oil content obtained from ripe FFB as mentioned by Harun and Noor [3], $K$ is mesocarp oil content calculated in \%, and 65 is the number of days for harvesting the FFB and also is the initial day of development with $0 \%$ mesocarp oil content FFB. The maximum of mesocarp oil content, $75 \%$, and $L$ were obtained by the chemical analysis of Soxhlet extractor in the laboratory. The zero day was meant for the actual harvesting day for FFB at $75 \%$ oil content and $N$ is the day calculated.

Assuming that the value of $K$ is 35\% mesocarp oil content. From Figure 5 and flow chart, the number of days before harvesting will be 35 days. 


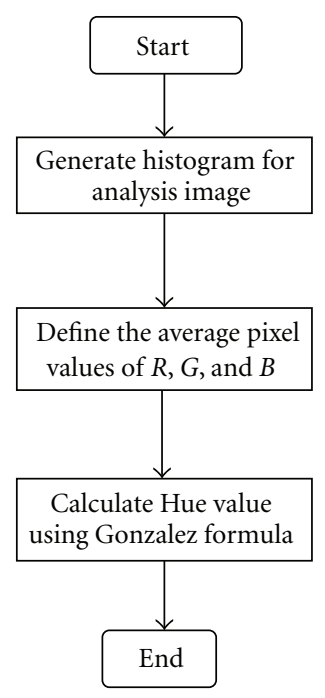

FIGURE 2: Flow chart for calculating the Hue digital value.

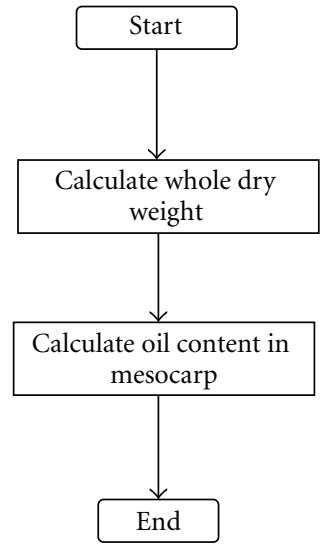

FIgURE 3: Flow chart for calculating oil content.

\section{Result and Discussion}

The MPOB colorimeter was used to determine the ripeness of oil palm fruit based on mesocarp surface color. This equipment was used in this study to validate the ripeness of the oil palm fruits after determining the mesocarp oil content using Soxhlet extraction process. Figure 6 shows the relationship of the Hue digital value with oil palm fruit maturity level. From the Table 1, the Hue value of 158 to 179 indicates unripe FFB, 185 to 212 indicates underripe FFB and 224 to 255 indicates ripe FFB.

3.1. Estimation for Harvesting the 20-Year-Old FFB. The suitable days for harvesting were calculated based on equation. The model for maturity simulation was based on linear interpolation method in determining the maximum oil content which was assigned as ripe FFB and the date for harvesting. Harun and Noor [3] mentioned that the $75 \%$ of oil to dry mesocarp indicated the ripe FFB. The experiments dates were manipulated for linear interpolation so that the day for harvesting the FFB with at 75\% mesocarp oil content, meant zero day for harvesting is determined. The ripeness

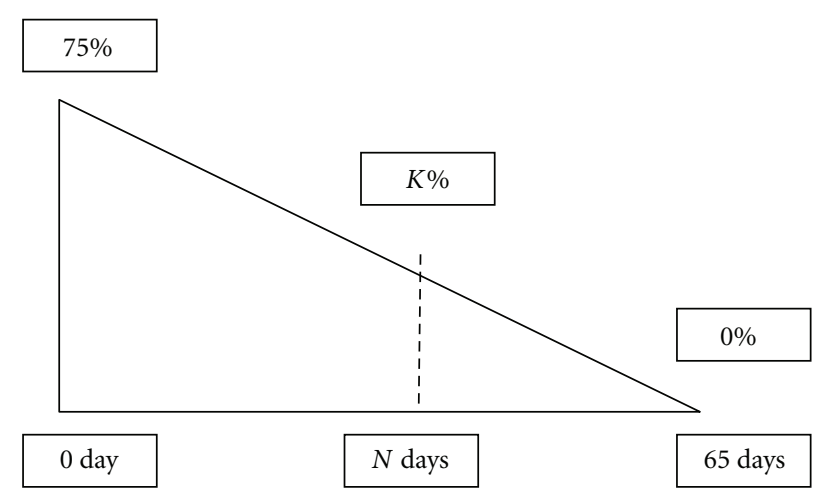

Figure 4: The method to determine the harvesting days.

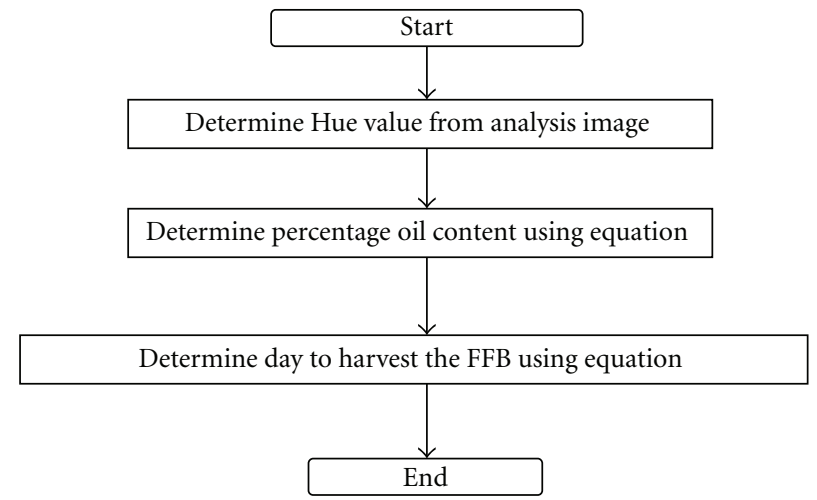

FIGURE 5: Flow chart for calculating the harvesting day of FFB.

TABLE 1: The correlation of moisture content and weeks of fruits after anthesis (adapted from [1]).

\begin{tabular}{lc}
\hline Maturity stage & Moisture content \\
\hline Under ripe, less than 18th weeks after anthesis & $40 \%-80 \%$ \\
Nearly ripe, 18th to 20th weeks & $35 \%-40 \%$ \\
Ripe, 20th to 22nd weeks & $33 \%-35 \%$ \\
Fully ripe, 23rd onwards & Less than 33\% \\
\hline
\end{tabular}

stage of FFB was confirmed on visual image evaluation. Figure 7 shows the estimation model of mesocarp oil content with harvesting day prediction. High correlation of $R^{2}$ found for relationship of mesocarp oil content versus date for harvesting with equation of $Y=-1.3295 X+71.503$ and regression squared, $R^{2}=0.81$ was high and acceptable. The linear regression method was used to generate an equation for interpolating the days required for harvesting the FFB. From the graph, the oil starts to develop the fruit before 54 days to harvest the FFB for 20 years old oil palm fruits.

Figure 8 shows the model to predict the harvesting days for FFB 20-year-old oil palm tree. The graph relationship of mesocarp oil content with Hue digital value was combined with the graph of mesocarp oil content with days to harvest FFB (indicated as red line). The mesocarp oil content was found developed at 54 days before harvesting the FFB. The zero day meant the day for harvest the FFB at maximum mesocarp oil content of 75\% (indicated as blue dash line). 


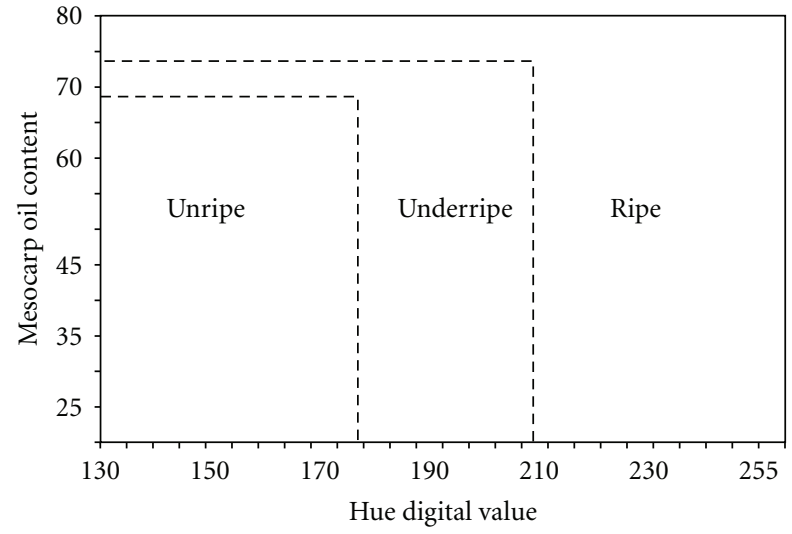

Figure 6: The relationship of the Hue digital value in relation to maturity level of oil palm FFB.

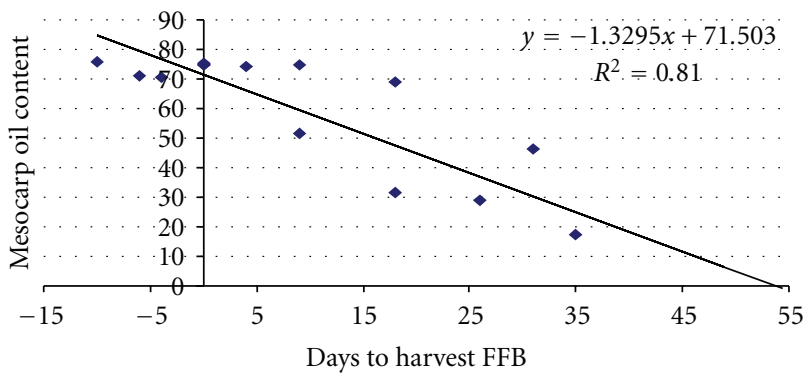

FIGURE 7: Estimation model of mesocarp oil content for harvesting date prediction.

Figure 8 is used as a standard graph to predict the harvesting days for FFB of 20 years old.

3.2. Estimation for Harvesting the 16-Year-Old FFB. The data included for harvesting the 16-year-old FFB also was published as mentioned by Razali et al., [4]. Otherwise there is a need to find a relationship between the age of FFB cycle time on all data experiments; for earlier time of harvestings was at 5 years old, 16 years old stand as at middle while 25 years stand as at the end of time cycle for FFB. Figure 9 shows the estimation model of mesocarp oil content for harvesting date prediction. High correlation of $R^{2}$ found for relationship of mesocarp oil content versus date for harvesting with equation of $Y=-1.125 X+76.386$ and regression squared, $R^{2}=0.904$ was high and acceptable. The oil was developed in the fruit at 66 days before harvesting the FFB for 16-year-old oil palm fruits.

Figure 10 shows the model to predict the harvesting days for FFB 16 years old oil palm tree. The graph relationship of mesocarp oil content with Hue digital value was combined with the graph of mesocarp oil content with days to harvest FFB (indicated as red line). The mesocarp oil content was found developed at 66 days before harvesting the FFB. Along 66 to 0 days, the minor unit in the graph was divided into 35 , and every unit had 1.89 days. The zero days meant the day for harvest the FFB at maximum mesocarp oil content of $75 \%$, (indicated as blue dash line). Let us say if the captured

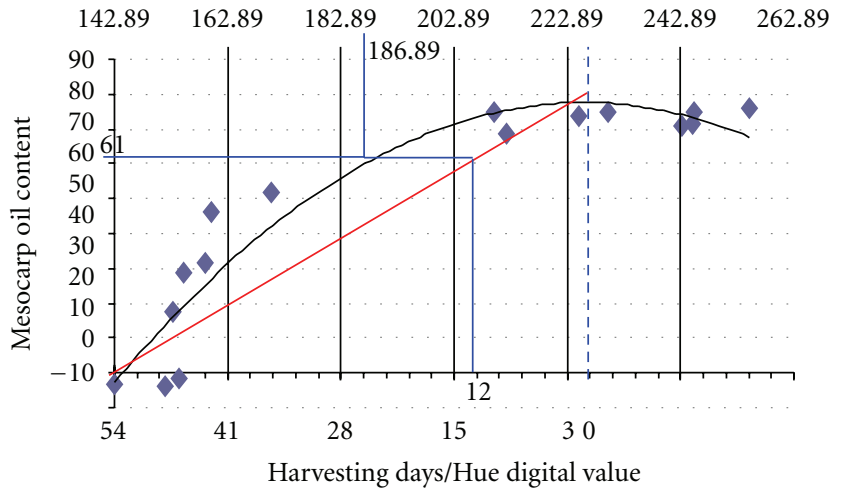

- Mesocarp oil content versus Hue digital value
_- Mesocarp oil content versus harvesting days
_- Date to harvest FFB

FIGURE 8: The model of the harvesting days for FFB 20-year-old oil palm tree.

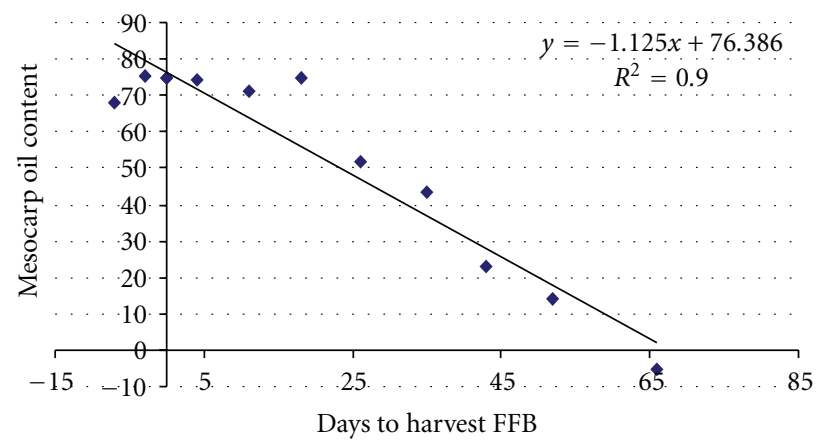

FIGURE 9: Estimation model of Mesocarp oil content for harvesting date prediction.

image of FFB had Hue of 180 , the oil content was $57 \%$, and the fruit will require 17 days or 408 hours for harvesting the FFB (indicated as blue line).

3.3. Estimation for Harvesting the 5 Year-Old FFB. Figure 11 shows the estimation model of mesocarp oil content for harvesting date prediction. High correlation of $R^{2}$ found for relationship of mesocarp oil content versus date for harvesting with equation of $Y=-0.1547 X+74.279$ and regression squared, $R^{2}=0.80$ was high and acceptable. From the graph, the oil content was $65 \%$ developed in the fruit at 60 days before harvesting the FFB for 5 year-old oil palm fruits.

The regression squared of $R^{2}$ for 5 years old tree FFB was found low compared with 16 and 20 years old. That was due to experiment date did not start at $0 \%$ mesocarp oil content. In actual experiment, we do not know the content of the oil in the fruit FFB. The determination of fruits mesocarp oil content was only measured using the basis procedure of standard bunch analysis. The Soxhlet extractor machine, oven, and so forth were used during experiment as earlier discussed. Figure 12 shows the model predicting the harvesting days for FFB 5 years old oil palm tree. The graph 


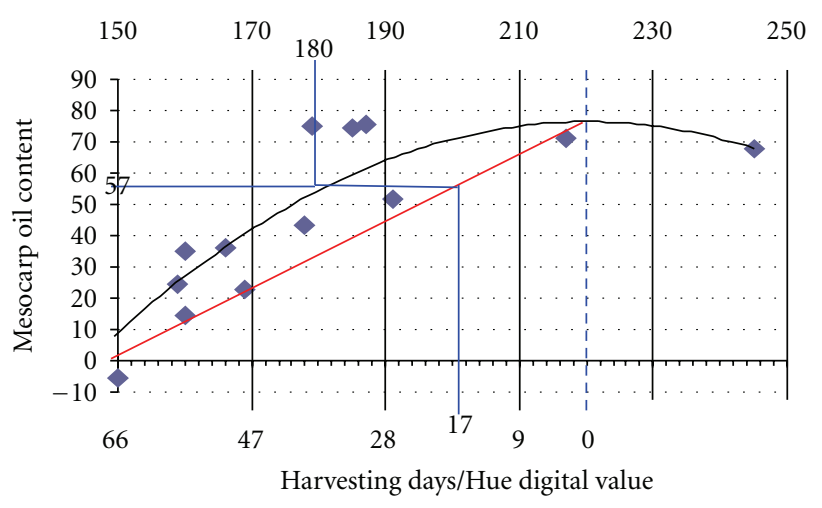

_ Mesocarp oil content versus Hue digital value
__ Mesocarp oil content versus harvesting days

Figure 10: The model of the harvesting days for FFB 16 years old oil palm tree.

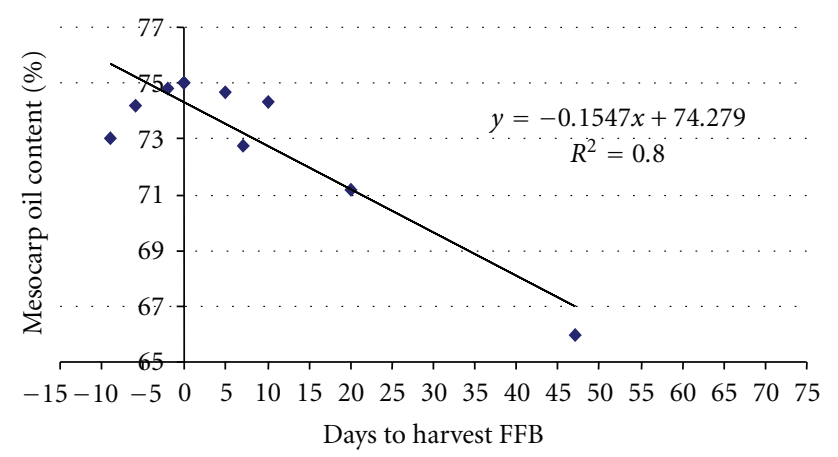

FIGURE 11: Estimation model of mesocarp oil content for harvesting date prediction.

relationship of mesocarp oil content with Hue digital value was combined with the graph of mesocarp oil content with days to harvest FFB (indicated as red line). The mesocarp oil content was found $65 \%$ developed at 60 days before harvesting the FFB. Along 60 to 0 days, the minor unit in the graph was divided into 46 and every unit had 1.30 days. Zero day meant the day for harvest the FFB at maximum mesocarp oil content of $75 \%$ (indicated as blue dash line). Let us say if the captured image of FFB had Hue of 200, the oil content was $69.8 \%$, and the fruit will require 33 days or 792 hours for harvesting the FFB (indicated as blue line).

3.4. Overall Estimation for Harvesting the FFB. Figure 13 shows the overall estimation model of mesocarp oil content for harvesting days prediction of FFB of 20, 16, and 5 years old oil palm tree. High correlation of $R^{2}$ found for relationship of mesocarp oil content versus date for harvesting with equation of $Y=-1.1405 X+73.719$ and regression squared, $R^{2}=0.81$ was acceptable. From the graph in Figure 12, the oil was found to start developing in mesocarp fruit at 65 days before fruit at ripe maturity stage with indicated $75 \%$ oil to dry mesocarp.

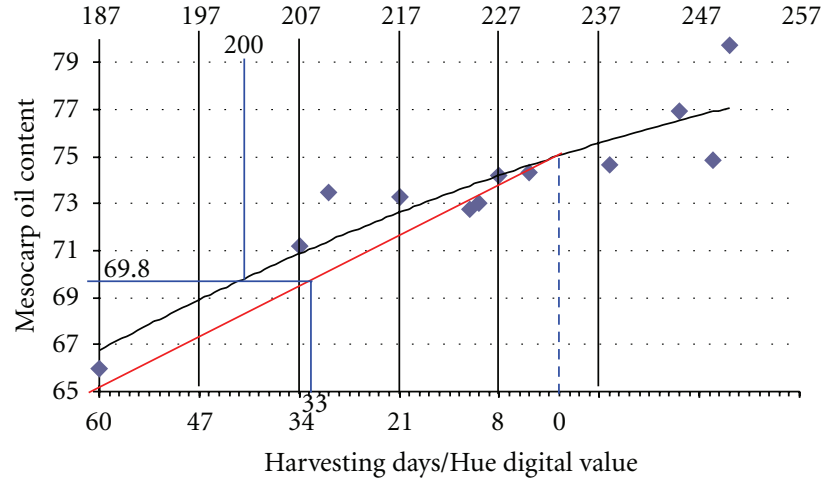

— Mesocarp oil content versus Hue digital value

_ Mesocarp oil content versus harvesting days

- - Date to harvest FFB

FIGURE 12: The model of the harvesting days for FFB 5 years old oil palm tree.

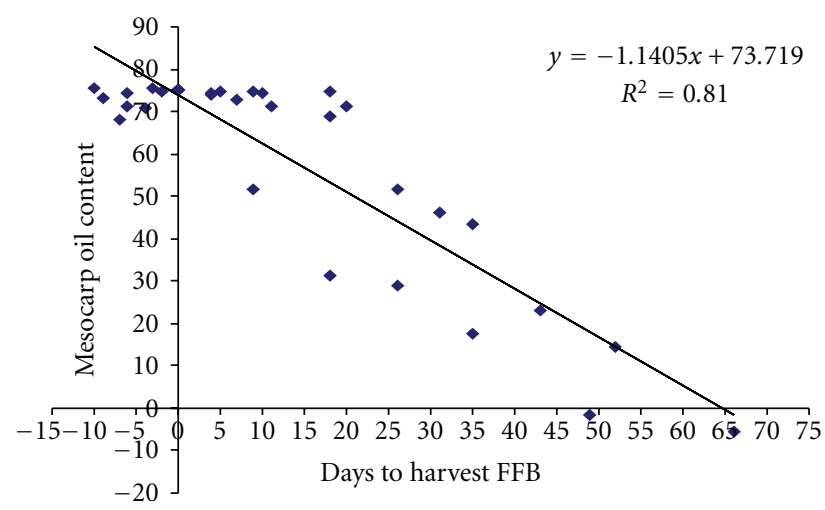

Figure 13: Overall estimation model of mesocarp oil content and harvesting days prediction.

The relationship between mesocarp oil content with Hue value of the FFB can be expressed by the following equation:

$$
Y=-0.0116 X^{2}+5.2376 X-514.88,
$$

where $Y$ is mesocarp oil content in $\%$ and $X$ is Hue value. The mesocarp oil content was determined by Hue digital value using equation of (7). The Nikon digital camera used to capture the FFB image before uploading into analysis software that was developed using programming source code of Visual Basic. Figure 13 shows the estimation model of mesocarp oil content and harvesting days prediction for oil palm FFB. The harvesting days was determined based on the $75 \%$ mesocarp oil content which indicated as a ripe stage for FFB [3]. Linear interpolation technique is used to fix the date for the oil content of mesocarp reaching at $75 \%$ as earlier discussed. The harvesting days of FFB was determined by percentage of mesocarp oil content using linear equation as shown in Figure 14. The development of oil in mesocarp fruit starts at 65 days before fruit at ripe maturity stage. Along 65 to 0 days, the minor unit in the graph was divided into 66 and every unit had 2.10 days for harvesting the FFB. Zero days meant the day for harvesting the FFB with maximum 


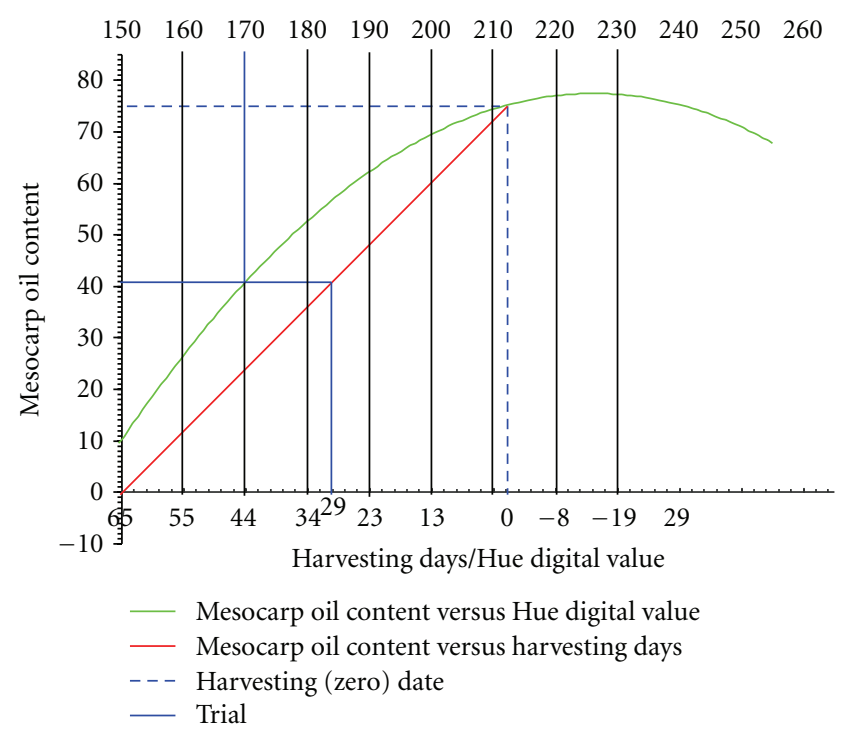

FIGURE 14: The graph for determining the day of harvesting the FFB.

mesocarp oil content of 75\% (indicated as blue dash line). Let us say if the captured image of FFB had Hue of 170, the oil content was $41 \%$ and the fruit will require 29 days for harvesting the FFB (indicated as blue line).

3.5. Validation of Day Estimation Simulation for Harvesting the FFB. A fruit bunch normally takes around 20 to 22 weeks to ripen after anthesis [5-7]. In this experiment, the time taken for FFB to ripe and to be harvested was 22 weeks after the flower fully open for pollination process (anthesis). Similar finding was also mentioned by Khalid and Abbas [1] where they had developed a microstrip sensor in order to determine the harvesting day for oil palm fruits. They mentioned mesocarp moisture content can indicate the age of the fruits, in terms of number of weeks, after anthesis. Table 1 shows the correlation of moisture content and the age of the fruits after anthesis with respect to number of weeks before harvesting time. It means that from Hue value of the FFB image, the number of days required for optimum harvesting is approximately 14 days or within 2 weeks. Khalid and Abbas [1] were claimed that his method is better on assessing the fruit maturity by its accuracy and time efficiency compared with traditional fruit picker. Otherwise the element of contact measurement method was overcome by this research study. On actual experiment, the FFB was considered matured when there were loose fruits found laying on the ground, that was after 65 days of constant monitoring starting from unripe stage (also confirmed after running the mesocarp oil extraction). The suitable days for harvesting were calculated based on (11) which indicates maximum $75 \%$ oil to dry Mesocarp of $[3,8]$.

That was an agreement, the FFB normally took around 20 to 22 weeks to ripen after anthesis [5-7]. Thus, the developed simulation model to predict harvesting day for the FFB was similarly established by Khalid and Abbas [1]. They used the harvesting period in number of weeks which still in a range for harvesting day as in this research. The prediction model for harvesting based on Hue value used in this project was more advanced compared to the used of microstrip sensor [9, 10]. Razali et al. [9] used the RGB (red, green, blue) color space scheme for predicting the maturity stage of outdoor FFB's image and found that only the red color space component having correlation with maturity index while the green and blue color space components were ignored. These make the Hue color component which stands for the whole color of FFB surface is found better compared with that the only red components effected in RGB color space. This method of work can be used in real-time prediction in an actual oil palm plantation, and this method also used nondestructive device application. The camera can shoot the image even from the ground level rather than to pick the sample fruit on the tree in order to run the microstrip sensor application [4].

\section{Conclusion}

The estimation of day harvesting prediction was calculated based on developed model of relationships for Hue values with mesocarp oil content. When the standard camera captures the FFB image, the image will be analysed using Hue digital values which correlate to the oil content of the fruit mesocarp. The simulation model is regressed and predict the day of harvesting or a number of days before harvest of FFB. The result from experimenting on mesocarp oil content can be used for real-time oil content determination of MPOB color meter. The graph to determine the day of harvesting the FFB was contributed in this research. The oil was found to start developing in mesocarp fruit at 65 days before fruit at ripe maturity stage of $75 \%$ oil-to-dry mesocarp.

\section{Acknowledgments}

The authors are thankful to all staff members especially from Department of Agriculture and Biological Engineering, Universiti Putra Malaysia, Serdang, Selangor, Malaysia which provided all materials and tools for conducting this research.

\section{References}

[1] K. Khalid and Z. Abbas, "Microstrip sensor for determination of harvesting time for oil palm fruits (tenera. Elaeis guineensis)," Journal of Microwave Power and Electromagnetic Energy, vol. 27, no. 1, pp. 3-10, 1992.

[2] M. Z. Abdullah, C. G. Lim, and B. M. N. M. Azemi, "Stepwise discriminant analysis for colour grading of oil palm using machine vision system," Food and Bioproducts Processing, vol. 79, no. 4, pp. 223-231, 2001.

[3] M. H. Harun and M. R. M. Noor, "Fruit set and oil palm bunch components," Journal of Oil Palm Research, vol. 14, no. 2, pp. 24-33, 2002.

[4] M. H. Razali, W. I. W. Ismail, A. R. Ramli, M. N. Sulaiman, and M. H. Harun, "Development of image based modeling for determination of oil content and days estimation for harvesting of fresh fruit bunches," International Journal of Food Engineering, vol. 5, no. 2, pp. 1633-11637, 2009.

[5] K. T. Ng and A. Southworth, Optimum Time of Harvesting Oil Palm Fruits, Incorporated Society of Planters, Kuala Lumpur, Malaysia, 1973. 
[6] I. M. Siregar, "Assessment of ripeness and crop quality control," in Proceeding of the Malaysian Inter Agricultural Oil Palm Conference, pp. 740-754, Kuala Lumpur, Malaysia, 1976.

[7] A. A. Azis, "A simple floatation technique to gauge ripeness of oil palm fruits and their maximum oil content," in Proceeding of the International Palm Oil Development Conference (PORIM '90), pp. 87-91, Kuala Lumpur, Malaysia, 1990.

[8] W. I. W. Ishak and R. M. Hudzari, "Image based modeling for oil palm fruit maturity prediction," Journal of Food, Agriculture and Environment, vol. 8, no. 2, pp. 469-476, 2010.

[9] M. H. Razali, W. I. wan Ismail, A. R. Ramli, and M. N. Sulaiman, "Modeling of oil palm fruit maturity for the development of an outdoor vision system," International Journal of Food Engineering, vol. 4, no. 3, pp. 1396-1396, 2008.

[10] M. R. Hudzari, W. I. W. Ismail, A. R. Ramli, M. N. Sulaiman, and M. H. B. Harun, "Prediction model for estimating optimum harvesting time of oil palm fresh fruit bunches," Journal of Food, Agriculture \& Environment, vol. 9, no. 3, 4, pp. 570-575, 2011. 

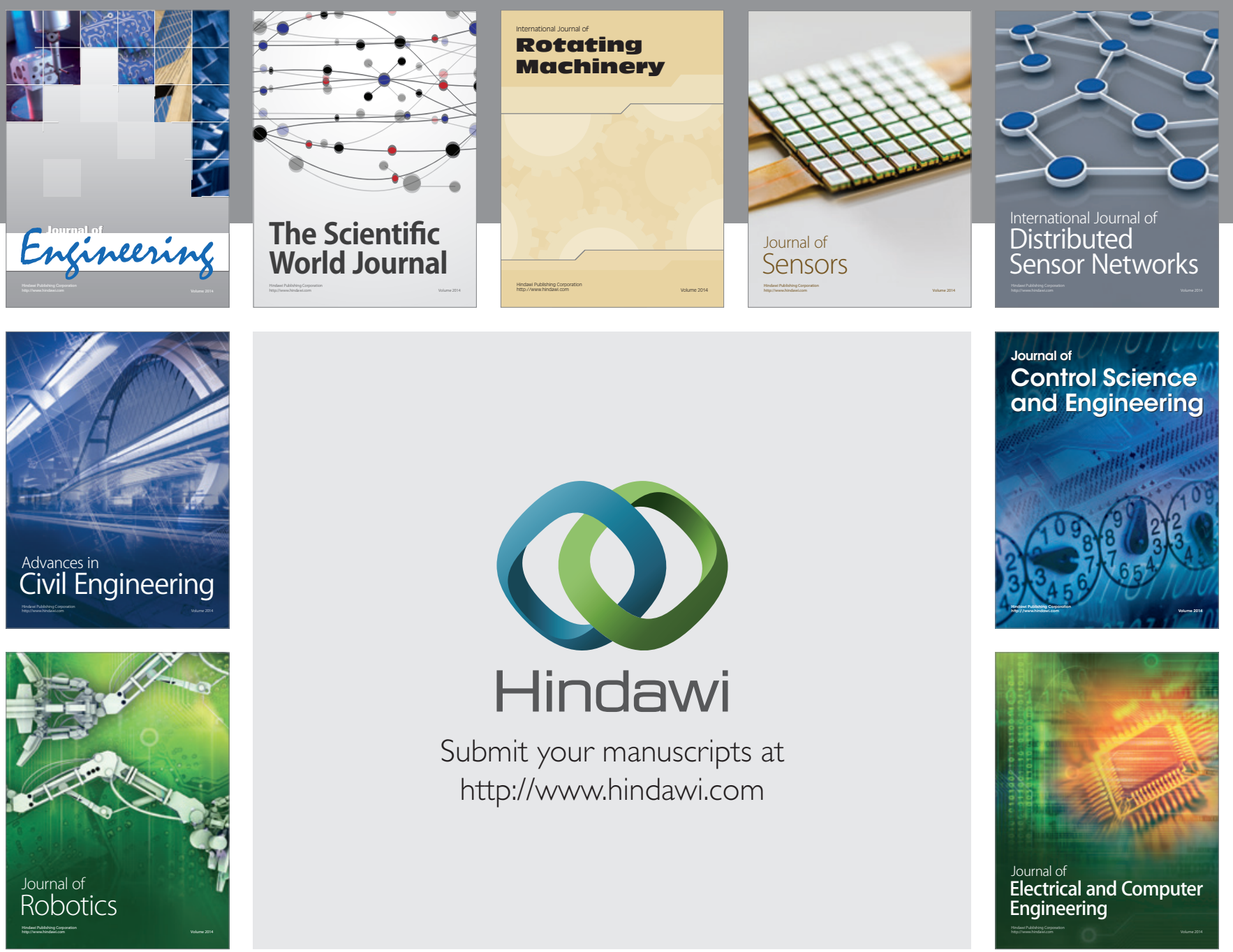

Submit your manuscripts at

http://www.hindawi.com
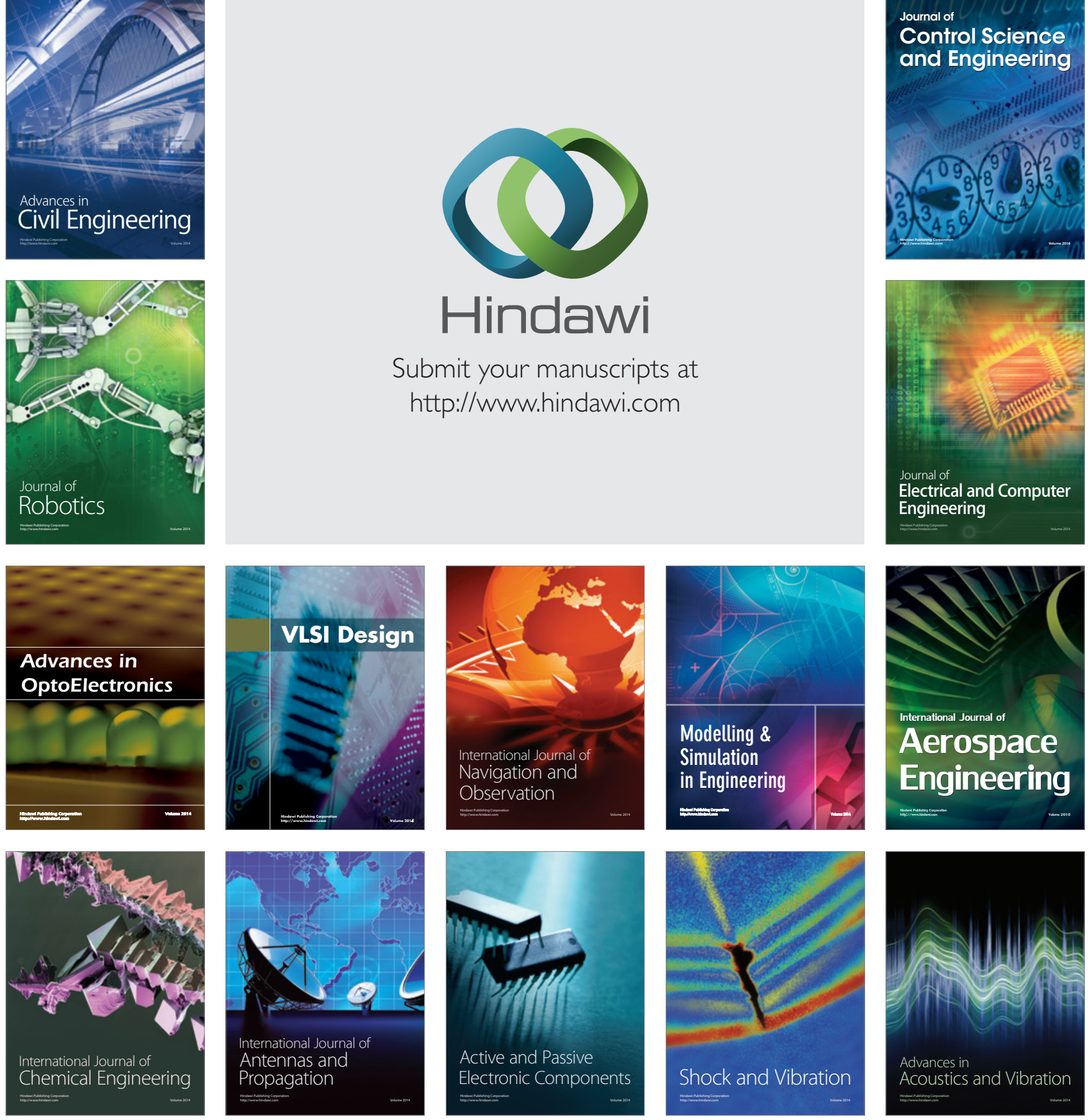